ÚLTIMA DÉCADA, N46, JULIO 2017, PP. 147-183

\title{
TIPIFICACIONES JUVENILES SOBRE LA VIOLENCIA EN EL ESCENARIO ESCOLAR
}

\author{
CARINA V. KAPLAN ${ }^{1}$ \\ PABLO DI NAPOLI ${ }^{2}$
}

\begin{abstract}
RESUMEN
El presente trabajo indaga las imágenes que los estudiantes construyen en torno a las y los jóvenes que tipifican como “violentos”. Se centra en el análisis de las cualidades que utilizan para adjetivarlos en tanto que formas de nominación y prescripción de comportamientos. Para ello, se recupera la perspectiva del constructivismo estructuralista de Pierre Bourdieu en torno al poder simbólico de los actos de clasificación escolar. El estudio socioeducativo de corte cualitativo se basa en un corpus de sesenta entrevistas en profundidad realizadas a estudiantes de dos escuelas secundarias de la provincia de Buenos Aires en Argentina.
\end{abstract}

PALABRAS CLAVE: NOMINACIÓN Y CLASIFICACIÓN ESCOLAR, ESTIGMATIZACIONES

SOBRE LA VIOLENCIA, JÓVENES ESTUDIANTES.

${ }^{1}$ Doctora en Educación por la UBA y Magíster en Ciencias Sociales y Educación por la FLACSO, Argentina. Posdoctorado en la Universidad Estadual de Rio de Janeiro. Profesora Titular Ordinaria de Sociología de la Educación en el Departamento de Ciencias de la Educación de la FaHCE de la UNLP y Profesora Adjunta Regular del Departamento de Ciencias de la Educación en la FFyL de la UBA a cargo de las cátedras de Sociología de la Educación y de Teorías Sociológicas. Investigadora Independiente del CONICET. Directora del Programa de Investigación sobre Transformaciones sociales, Subjetividad y Procesos educativos del IICE- UBA. Email: kaplancarina@gmail.com

2 Doctor en Ciencias Sociales y Licenciado y Profesor en Sociología por la UBA, Argentina. Docente de la cátedra de Teorías Sociológicas del Departamento de Ciencias de la Educación de la FFyL de la UBA. E-mail: pablodinapoli@filo.uba.ar 


\title{
TIPIFICAÇÕES JUVENIS SOBRE A VIOLÊNCIA NO CENÁRIO ESCOLAR
}

\begin{abstract}
RESUMO
O seguinte trabalho indaga as imagens que os estudantes constroem em torno das e dos jovens que tipificam como "violentos”. É concentrado na análise das qualidades que utilizam para adjetivá-los enquanto que formas de nominação e prescrição de comportamentos. Para isto, foi recuperada a perspectiva do construtivismo estruturalista de Pierre Bourdieu em torno do poder simbólico dos atos de classificação escolar. O estudo socioeducativo de corte qualitativo está baseado em um corpus de sessenta entrevistas em profundidade realizadas a estudantes de duas escolas secundárias da província de Buenos Aires na Argentina.
\end{abstract}

\author{
PALAVRAS-CHAVE: NOMINAÇÃO E CLASSIFICAÇÃO ESCOLAR - ESTIGMATIZAÇÃO \\ SOBRE A VIOLÊNCIA - JOVENS ESTUDANTES.
}

\section{YOUTH TYPIFICATIONS ON VIOLENCE IN SCHOOL}

\begin{abstract}
The present work focuses on the images constructed by students around young men and women typified as "violent", from the analysis of the qualities used to adjectivize them as forms of behavior nomination and prescription. For this, Pierre Bourdieu's perspective about structural constructivist theories about the symbolic power of school classification acts is recovered. The socio-educational qualitative study is based on a corpus of sixty in-depth interviews with students from two high schools in the province of Buenos Aires, Argentina.

KEYWORDS: NOMINATION AND SCHOOL CLASSIFICATION - STIGMATIZATIONS ABOUT VIOLENCE - YOUNG STUDENTS.
\end{abstract}




\section{INTRODUCCIÓN}

Desde una perspectiva de larga duración, la categoría de juventud es depositaria del estigma de la violencia. “Joven” y “violento” suelen ser adjetivaciones mutuamente incluyentes cuyo vínculo tiene una génesis histórica. Si nos remontamos al renacimiento europeo, encontramos que existía una cultura de la virilidad que exaltaba la violencia en los adolescentes, potenciada en los abbayes de juventud, cuyos excesos sanguinarios eran tolerados por los jefes de familia (Aymard, 1991). Según Bourdieu (1990), la ideología de la virilidad y la violencia propuesta a los jóvenes de esa época era una de las formas que tenían los adultos de reservarse para sí otras virtudes tales como la sabiduría, asociadas con el poder de gobernar.

Mediante el aumento de las redes de interdependencia social y la progresiva monopolización de la violencia física por parte de los nacientes Estados modernos, se produjo un proceso de pacificación de las costumbres por el cual se les prohibió a los individuos la libre disposición sobre los medios militares, así como también se volvió ilegítima e intolerable el uso de la fuerza física en el trato social. (Elias, 2011). En este marco, se fue construyendo una imagen sobre la adolescencia como una edad turbulenta cuyos excesos sanguinarios ahora debían ser castigados y encauzados bajos nuevas formas de control y procesos educativos. Así, el ser joven se transforma poco a poco “...en una condición estigmatizante, esto es, portador de un atributo concebido como intrínseco que tiene la cualidad de vergonzante y amenazador” (Kaplan, 2012: 20).

A través del lenguaje penal "la imagen de brutalidad excesiva que había predominado para todos, se irá haciendo más selectiva y se imputará a una minoría juzgada como 'anormal' que se abandona a los golpes y a las lesiones (...)” (Kaplan, 2013b: 115). La categoría de delincuencia juvenil, acuñada a mediados del siglo XIX, operará como un separador jurídico y social, de corte 
clasista, entre la juventud “dorada” y la juventud "turbulenta” calificada como violenta (Muchembled, 2010).

Esta breve referencia histórica da cuenta de la matriz social de la cual provienen los discursos e imágenes contemporáneas que asocian la condición juvenil subalterna con la violencia delictual. En la actualidad, la escuela secundaria suele aparecer representada por los medios de comunicación como un espacio atravesado por la violencia que protagonizan las y los jóvenes (Sáez, 2015). Sin embargo, las investigaciones del campo socioeducativo que indagan sobre las violencias en las escuelas evidencian que las manifestaciones más extendidas en el ámbito escolar no son precisamente aquellas que se encuentran tipificadas por el código penal y/o que ponen en riesgo la integridad física de los individuos, sino que son resultado de conflictos de baja intensidad (Abramovay, 2006; Furlan, 2012; Kaplan, 2009; Kornblit, 2008; Mejía Hernández, 2013; Míguez, 2008; Paulín \& Tomasini, 2008; Viscardi, 2002). Es en la dinámica intersubjetiva de las relaciones que tienen lugar en la cotidianeidad escolar donde las prácticas de violencia, física y simbólica, cobran su sentido más profundo.

La violencia porta un componente relacional y emocional. Por ello, resulta importante detenerse a analizar las formas de sociabilidad de las y los jóvenes en la escuela y en el aula. Una nota característica de la condición juvenil es el poder simbólico que ejerce lo grupal en sus interacciones. El grupo de pertenencia cobra un lugar vertebrador de la sociabilidad y de los procesos de identificación colectiva de las y los jóvenes ${ }^{3}$. La mirada del otro, la identidad del yo, la mismidad, se funde en un nosotros a quienes es imperioso descifrar. Abram de Swaan (2011) sostiene que los actos de violencia constituyen, en última instancia, enfrentamientos entre un ellos y un nosotros.

\footnotetext{
${ }^{3}$ En un trabajo reciente hemos analizado las formas de sociabilidad de los jóvenes en el ámbito escolar a partir de los motivos de agrupamiento y distanciamiento que esgrimían (di Napoli, 2017).
} 
La formación de grupos y el mantenimiento del grupo implican la inclusión y la exclusión al mismo tiempo, es decir, una 'interacción interior intensa contra una exterior limitada', separación espacial y, sobre todo, el correlato socio-psicológico de la identificación, por una parte y la desidentificación, por la otra. (De Swaan, 2011: 6-7).

Se abre el interrogante sobre los aspectos que los estudiantes tienen en cuenta para identificarse moral y afectivamente con ciertos jóvenes $y$ desidentificarse de otros a los cuales les atribuyen una menor valía social. Las señales de aceptación/inclusión o rechazo/exclusión hacia individuos o grupos son tácitas y, por eso, difíciles de "leer” o descifrar desde la posición adulta docente: las y los jóvenes suelen expresarse con pocas palabras, muchas miradas y alta emotividad. Como analiza Le Breton (2010) “toda interacción aparece pues como una negociación recíproca de la significación, sustentada en las palabras dichas, en los gestos, en las mímicas intercambiadas” (p. 108). Particularmente. El rostro constituye el prisma de la simbología donde se encarnan el lenguaje, los afectos y las emociones.

En este trabajo indagamos las imágenes que las y los estudiantes secundarios construyen sobre los jóvenes que tipifican como “violentos”. Particularmente, nos centramos en el análisis de las cualidades que les adjudican al nombrar y describir a aquellos sujetos. En los relatos de las y los estudiantes entrevistados subyacen discursos sociales estigmatizantes anclados en los modos de comportarse, la disposición corporal y el origen social percibido. Consideramos necesario desocultar los significados que operan en las estrategias discursivas que contribuyen a la naturalización de creencias dominantes.

El supuesto de partida de las reflexiones aquí expuestas se asienta sobre la idea de que en el ámbito escolar existe una lucha simbólica “(...) para caracterizar la violencia, para diferenciarla de la no violencia y, para responsabilizar a ciertos individuos y grupos” (Castorina \& Kaplan, 2006: 39). 
En el siguiente apartado recuperamos la perspectiva de Pierre Bourdieu y los estudios antecedentes de Carina Kaplan $(1992,2008)$ en torno al poder simbólico de los actos de nominación. Posteriormente, luego de describir brevemente la metodología del estudio, procedemos a examinar los calificativos que las y los estudiantes utilizan para caracterizar y establecer fronteras entre los jóvenes que consideran "violentos".

\section{FORMAS DE CLASIFICACIÓN SOCIAL EN TORNO A LA NOMINACIÓN DE “JOVEN VIOLENTO”}

El lenguaje, sabemos, no es neutro y su uso tampoco es inocente. En este escrito nos preguntamos cuáles son los términos que utilizan las y los estudiantes de educación secundaria para describir a los jóvenes que tipifican como "violentos". A fin de comprender los usos sociales de sus palabras, los significados y las relaciones de poder en las cuales se enmarcan, recurrimos a los trabajos de Pierre Bourdieu en torno a la economía de los intercambios lingüísticos. Aquí no pretendemos embarcarnos en un análisis lingüístico de los discursos de las y los estudiantes, sino más bien desentrañar sociológicamente las ideas y creencias naturalizadas que subyacen en los juicios que realizan sobre otros y otras jóvenes y sus potenciales efectos estigmatizantes.

El lenguaje tiene un poder simbólico, casi mágico, de ayudar a fabricar al nominar a un sujeto, a un objeto o a un hecho social. El uso de ciertas palabras (y no de otras) cobra sentido en un contexto social más amplio de intercambios simbólicos. Bourdieu (2014b) enfatiza que el acto cotidiano de nominar algo o a alguien contribuye a darle entidad y definirlo como tal en función de la autoridad que posee quien enuncia la nominación. Su efecto no radica tanto en la lógica meramente lingüística, sino en las relaciones entre las propiedades del discurso enunciado, el poder de la persona que lo pronuncia y el reconocimiento de la institución que lo autoriza (los medios de comunicación, los políticos, la escuela, la justicia, entre otros). 
Toda nominación supone un acto de clasificación en cuanto establece límites y fronteras entre lo que es y no es aquello que se tipifica, en nuestro caso particular, la delimitación entre las y los jóvenes “violentos” y “no violentos”. Pero la distinción entre unos y otros no solo implica una diferenciación, sino que también trae aparejado una ponderación de aquello que se designa, es decir, la asignación de un valor social.

En el clásico ensayo Sobre algunas formas primitivas de clasificación, Durkheim y Mauss (1996) ya advertían que "toda clasificación implica un orden jerárquico del que ni el mundo sensible ni nuestra conciencia nos brindan el modelo” (30). Esto significa, por un lado, que una clasificación conlleva un ordenamiento relacional por el cual se coloca algo por debajo o por encima de otra cosa. Por otro lado, dichos criterios de ordenamiento y jerarquización no están dados naturalmente desde el mundo exterior ni son producto del entendimiento individual, sino que se estructuran en base al modo de organización social que integran los individuos y grupos. Ahora bien, dado el carácter social del sistema de clasificaciones (taxonomías) resulta necesario tener presente que la imposición de determinados criterios, y no de otros, es el resultado de la relación de fuerzas (desiguales) de los agentes que los disputan.

La eficacia de las taxonomías sociales, su magia, consiste en invisibilizar la génesis social (las luchas simbólicas que están por detrás) de los principios de clasificación prácticos que utilizamos diariamente y percibirlos como dados, naturales o lógicos. Al ser reconocidos como lógicos le queda velado su carácter arbitrario. Justamente,

(...) el orden social debe su permanencia en parte al hecho de que impone esquemas de clasificación que, al ajustarse a las clasificaciones objetivas, producen una forma de reconocimiento de este orden que implica el desconocimiento de lo arbitrario de sus fundamentos: la correspondencia entre las divisiones objetivas y los esquemas clasificatorios, y entre las estructuras objetivas y las estructuras mentales, constituye el fundamento 
de una especie de adhesión originaria al orden establecido. (Bourdieu, 2014a: 123-124)

Estas formas de ver, pensar y sentir el mundo social en el cual estamos inmersos nos atraviesa en lo más hondo de nuestra subjetividad y en los vínculos que construimos con otros. Se trata de esquemas de percepción que vamos incorporando en nuestros cuerpos socializados a lo largo de experiencias (individuales y colectivas) acumuladas. En estas experiencias las emociones no son ajenas. De hecho, "el orden social se inscribe en los cuerpos a través de esta confrontación permanente, más o menos dramática, pero que siempre otorga un lugar destacado a la afectividad y, más precisamente, a las transacciones afectivas con el entorno social” (Bourdieu, 1999: 186). La eficacia de la doxa (aquellos esquemas de percepción habituales que guían nuestra práctica cotidiana y sobre los cuales no reflexionamos) se asienta tanto en el intelecto como en lo más íntimo de nuestras emociones. Opera “(...) a través del lenguaje, del cuerpo, de actitudes hacia las cosas que están por debajo del nivel de la conciencia” (Bourdieu \& Eagleton, 2003: 300).

A través de los principios de visión y división del mundo social que incorporamos desde pequeños, emitimos juicios hacia otros así como también somos objeto de clasificación e, incluso, nos autoevaluamos en función de dichos principios. Por ello, las taxonomías sociales tienen un impacto en nuestra autoestima e identidad social (Kaplan, 2008).

Aquí cabe preguntarse, cuáles son las expectativas que se depositan sobre las y los jóvenes que se consideran "violentos”, así como también las que aquellos sujetos asumen de sí mismos. Dichas expectativas no son percibidas de forma pasiva sino que se forjan en la interacción cotidiana con los otros y son objeto de permanentes luchas simbólicas.

Por medio de los juicios, las clasificaciones y los veredictos, que recibimos y efectuamos, vamos realizando, de manera no necesariamente 
consciente, un cálculo simbólico (Kaplan, 2008) sobre nuestros límites y posibilidades.

El sujeto hace suyo un juicio público, legitimado por la institución escolar y personalizado en las interacciones sociales cotidianas, transmutando un principio de calificación colectiva en un acto de conciencia individual que, aunque de apariencia paradójica, le es oculto en cierto sentido. Esta incidencia simbólica que configura una suerte de efecto de destino (...) permite dar cuenta de una de las dimensiones significativas de la concreción de trayectorias estudiantiles diferenciales en la escuela. (Kaplan, 2008: 78)

La eficacia simbólica de las taxonomías radica en que transmutan las diferencias y desigualdades de carácter social en cuestiones de capacidades o atributos individuales. En nuestro caso, a través de la asignación de etiquetas como la de "violento" se pone en juego una dinámica de poder por la cual se le concede a un sujeto ciertas cualidades asociadas a cierta adjetivación y un determinado valor social.

Las palabras y gestos de aprobación y descalificación que interiorizan las y los estudiantes constituyen una cuestión medular para comprender la construcción de vínculos grupales en el ámbito escolar. La mayoría de los individuos de todas las sociedades tienen a su disposición un cúmulo de expresiones con las cuales estigmatizar a otras personas o grupos; sin embargo, como bien advierte Elias (1998), la eficacia de su uso se enmarca en figuraciones específicas donde existe una balanza de poder desigual entre diferentes grupos. En sintonía con los planteos de Bourdieu, Elías sostiene que el daño que pueden causar ciertos términos

(...) depende de la conciencia que tengan tanto quien los emplea como a quien se refiere, de que la humillación del último intencionada por quien los emplea, cuenta con el respaldo de un grupo claramente más poderoso 
con respecto al del receptor, que es un grupo marginal con recursos inferiores de poder. (Elias, 1998: 96)

En este marco, los miembros de grupos establecidos suelen hallar un aliado en la voz interior de quienes pertenecen a grupos marginados y se autoevalúan de acuerdo a los parámetros sociales de los primeros.

Analizar la imagen que fabrican las y estudiantes secundarios sobre las y los jóvenes que tipifican como "violentos" simboliza un modo de conocer cómo ellos mismos procesan las diferencias entre sí en un espacio social jerarquizado donde algunos individuos o grupos se auto-perciben superiores y otros son considerados de menor crédito social.

\section{CONSIDERACIONES METODOLÓGICAS}

Los resultados que se presentan a continuación son parte de una investigación doctoral ${ }^{4}$ cuyo objetivo general fue comprender las percepciones de los jóvenes estudiantes en torno a las violencias. El trabajo de campo se realizó en dos escuelas secundarias (medias) de gestión estatal del partido de Avellaneda, provincia de Buenos Aires (Argentina). Durante el año 2012 se llevaron a cabo entrevistas en profundidad con estudiantes de $3^{\text {er }} 4^{\text {to }}$ y $5^{\text {to }}$ año ${ }^{5}$. La guía de entrevistas constaba de cinco ejes temáticos sobre los cuales intercambiar en la conversación. Constituían pautas de exploración abiertas a la posibilidad de abordar aspectos emergentes (Bourdieu, 2013). En este trabajo nos centramos fundamentalmente en el eje referido a la caracterización de las y los jóvenes tipificados como "violentos". En total se entrevistaron

${ }^{4}$ La tesis doctoral de Pablo di Napoli fue dirigida por Carina V. Kaplan y realizada en el marco del Programa de Investigación sobre "Transformaciones Sociales, Subjetividad y Procesos Educativos" con sede en el Instituto de Investigaciones en Ciencias de la Educación (IICE) de la Universidad de Buenos Aires.

${ }^{5}$ Bajo los lineamientos de la Ley de Educación Nacional ( $\left.N^{\circ} 26.206\right)$ sancionada en el año 2006, la provincia de Buenos Aires opto por el establecimiento de un nivel secundario de 6 años (Ley Provincial de Educación N 13.688). 
individualmente 60 estudiantes: 26 en la escuela A y 34 en la escuela B. Los estudiantes entrevistados de la escuela A eran mayoritariamente de sectores populares, algunos de los cuales vivían en asentamientos urbanos precarios de la zona. En el caso de la escuela B, los alumnos con quienes dialogamos eran mayormente de sectores socioeconómicos medios.

Para el análisis de los datos se siguieron principalmente los lineamientos del análisis temático, el cual supone el reconocimiento de patrones dentro de los datos donde los temas emergentes devienen en categorías analíticas. Utilizando como soporte informático el programa Atlas.ti 7.0 se realizó una codificación y categorización por medio de un procedimiento mixto complementariamente inductivo-deductivo delimitando núcleos temáticos y categorías con mayor contenido inferencial (Miles \& Huberman, 1994).

A los fines de mantener el anonimato y preservar la confidencialidad e identidad de los estudiantes entrevistados se modificaron cada uno de sus nombres. En cada testimonio citado se especifica entre paréntesis el género, el año de cursada, el turno al que asisten ${ }^{6}$ y la escuela de pertenencia.

\section{HACIA LA CONSTRUCCIÓN SIMBÓLICA DE LAS Y LOS JÓVENES TIPIFICADOS COMO “VIOLENTOS"}

A partir de diferentes conflictos, peleas y agresiones que las y los estudiantes nos fueron narrando, les solicitamos que describieran a aquellos jóvenes que considerasen “violentos”. Nuestro interés se centró en indagar cuáles son las asociaciones de sentido que ponen en juego al construir imágenes de una otredad de la cual son parte: compañeros de sus escuelas, estudiantes de colegios cercanos o jóvenes con los que se cruzan en otros espacios de

\footnotetext{
${ }^{6}$ Para indicar el turno al que asisten los estudiantes utilizaremos las siguientes siglas: T.M. para el Turno Mañana y T.T. para el Turno Tarde.
} 
sociabilidad como partidos de futbol, redes sociales o locales bailables nocturnos.

\section{5. "BuSCAR PELEA".}

La disposición a "buscar pelea" es uno de los atributos por los cuales se tipifican a ciertos jóvenes como "violentos".

P: ¿Cómo me describirías a una persona que consideras violenta? Alguien de tu edad...

M: Y... una persona que se enoja por cualquier cosa, que no se le puede decir nada, que por todo quiere agarrarse a las piñas, que le decís algo y ya te quiere pegar... que constantemente está buscando a alguien para poder pelear, para poder agarrarse a las piñas ${ }^{7}$, ehhh... que viene de un entorno muy violento. No solo la familia, sino también los amigos, o capaz que el ambiente donde vive él.

\section{P: ¿En esta escuela hay estudiantes que sean de la forma que vos me contás?}

M: Puede ser, no los conozco mucho a todos a fondo (...). El año pasado sí había uno de mis compañeros (...) vivía agarrándose a las piñas, molestando, quería todo el tiempo pelear, por todo buscaba quilombo $^{8}$. (Alumno de 4to. T.M. - Escuela A)

\section{P: ¿Cómo eran, si los tuvieras que describir, qué hacían, [ex- estudiantes de la escuela]?}

D: Buscaban peleas... o sea vos ya los veías y buscaban peleas

${ }^{7}$ Significa agarrarse a golpes de puño.

${ }^{8}$ Quilombo es una palabra muy utilizada en el lenguaje cotidiano de los argentinos, incluido los jóvenes. En términos generales se usa para referir a un conjunto de significados tales como: "buscar, generar o estar en problemas"; estados de desorden o escándalo; mezcla o confusión de cosas; entre otros sentidos. 
siempre. Todos los problemáticos, los típicos problemáticos.

(Alumna de 5to. T.T. - Escuela B)

Al describirlos, continuamente hacen referencia a que: "les gusta pelear todo el día”, "están todo el tiempo queriendo pelear”, “de la nada buscan pelea", "personas que se enojan por cualquier cosa”, "que de la nada te quieren pegar”, “siempre van a la pelea”, “viven agarrándose a piñas”. En términos de Elias (2011) podríamos decir que se los presenta como personalidades poco autocoaccionadas. Las reacciones impulsivas frente a desavenencias con sus pares o la búsqueda constante de la confrontación para posicionarse por encima el otro son los primeros aspectos que mencionan las y los entrevistados.

En su análisis sobre la configuración emotiva de los individuos Elias (2011) sostiene que, a partir de una mayor red de interdependencia y un control social más intenso, con el paso del tiempo, se han producido cambios en nuestras formas de comportarnos posibilitándonos dominar “...las manifestaciones de la crueldad, la alegría producida por la destrucción y los sufrimientos ajenos, así como la afirmación de la superioridad física” (p. 184). Esto ocasionó un aumento de la sensibilidad a través de la cual las manifestaciones de impulsos agresivos fueron reprimidas y/o castigadas acompañadas por un sentimiento de desagrado. En palabras del sociólogo alemán “quien se sale del marco de las pautas emotivas sociales, pasa por «anormal»” (Elias, 2011: 197). Justamente a este aspecto apuntaron algunos entrevistados al describir a una persona “violenta” como alguien que "está loco". De este modo, encontramos en el par autocontrol/descontrol uno de los ejes de diferenciación, al menos discursivo, que esgrimen los estudiantes para establecer fronteras entre los jóvenes como “violentos” o “no violentos”.

El concepto de violencia es un término con una connotación moral negativa, a ella se asocia todo aquello que se considera "malo” o que está “mal”. Noel y Zucal (2010) sostienen que generalmente se utiliza este término 
“(...) para condenar prácticas o procesos que nos resultan desagradables o intolerables para sus enunciadores (...)” (99). La acción del otro se percibe como amenazante y se vuelve condenable.

Dada la percepción negativa de la palabra es esperable que nadie se autodefina a sí mismo de esa forma y que dicho atributo sea adjudicado a una otredad a la cual se refiere en términos de ellos. Incluso aquellos estudiantes que valoran el uso de la fuerza física en términos de aguante (Garriga Zucal, 2010), no se perciben como violentos al argumentar que no son ellos los que "buscan pelea".

A partir del uso de una etiqueta como la de "violento" podemos explorar cómo se expresa el sentido más profundo de las creencias implícitas de los estudiantes mediante prejuicios sociales, categorías estigmatizantes y discursos de corte racista que son incorporados social y culturalmente como resultado de sistemas de clasificación social dominantes que estructuran las formas de percepción. En estos procesos de asignación de tipificaciones "un comportamiento social de cierta cualidad -violento- pasa, de este modo, a ser tratado como un dato esencial de un tipo de individuo o de cierto grupo (Kaplan, 2012: 29)

La imagen que construyen simbólicamente los estudiantes está mediada por procesos de diferenciación/identificación centrados en pares dicotómicos jerárquicos: normal/anormal superior/inferior, bueno/malo, cheto $\%$ villero y blanco/negro. Las nominaciones y adjetivaciones socialmente peyorativas que utilizan para referirse a quienes consideran que "buscan pelea", operan como actos de clasificación con los cuales se los ubican en posiciones inferiores del espacio social y simbólico.

\footnotetext{
${ }^{9}$ Apócope de la palabra “concheto”, refiere a personas con alto poder adquisitivo o que ostentan de su apariencia y de sus posesiones materiales.
} 


\section{DE “NEGROS”, “VILLEROS” Y “ROCHOS”}

Van Dijk (2007) sostiene que la lexicalización o selección de las palabras para designar peyorativamente a otros es uno de los recursos de la lógica discursiva del racismo. En nuestro caso, encontramos tres términos utilizados de modo frecuente por los estudiantes para representarse a ciertos jóvenes: "negros", “villeros"10 y "rochos" 11.

G. es esa chica con la que me peleé, es re villera.

\section{P: Ah, ¿le dijiste?}

G: Sí, obvio, me quería pegar y le dije "sos una villera, no me voy a pelear con vos".

\section{P: ¿Qué es "ser villera"?}

G: Y... eso de querer pelear, o sea, primero una mujer no se pelea, y menos si no tenés un argumento o un buen motivo digamos. Porque si me decís que yo le hice algo, bueno, pero que se yo, para mí, es eso. (Alumna de 5to. T.M. - Escuela A)

D: (...) son pibes así de un ambiente medio, digamos, bajo.

\section{P: ¿A qué te referís con “ambiente bajo”?}

D: Pobres, tirando a la delincuencia digamos porque tienen aspecto así, portación de cara digamos, ¿no? (...)

\section{P: ¿Cómo es lo de la "portación de cara”?}

D: Y, cumbieros, así esa onda digamos, pero piercing, el corte rocha, o como se dice, corte bien bajo abajo. O la cresta, no es tan villera pero...

${ }^{10}$ El término originalmente refiere a los individuos que residen en asentamientos urbanos precarios y socialmente vulnerables.

11 Subversión de la palabra “chorro”. Dicho término designa a las personas que comenten robos. 


\section{P: ¿La "rocha” que significa?}

D: Ni yo lo sé pero en un principio se decían chorros escrito al revés, pero ahora como está más aceptado el ser chorro. Van más para el lado de la música tropical y cumbia. Y no tiene nada que ver porque yo escucho cumbia, y así y todo no me visto como un pibe villero. (Alumno de 5to. T.T. - Escuela B)

Estos términos constituyen expresiones racistas en cuanto asocian características intelectuales y culturales de un conjunto de individuos con atributos inscriptos en su naturaleza, a partir de los cuales se elaboran prácticas y discursos de inferiorización.

Coincidimos con Margulis (1999) en utilizar un concepto de racismo en sentido amplio, al asumir que el término ya no invoca “(...) exclusivamente a la noción de raza, sino que se refiere a la gama de rasgos y manifestaciones discriminatorias (...) centradas real o imaginariamente en el cuerpo, en el lugar de origen, en la cultura o en otra variable social (...)” (46).

La apelación a lo biológico es uno de los recursos más antiguos, y no por ello menos eficaces, para justificar las desigualdades que no son sino producto de las relaciones sociales de poder (Kaplan, 2008). En su invocación a la naturaleza, el cuerpo se convierte en un elemento central del racismo. Los rasgos corporales expresan la visibilidad de la diferencia, la afirmación de lo defectuoso y la portación de un estigma. Así, se facilita la identificación del otro y se esencializa la marca de su inferioridad humana y social (Elias, 1998; Goffman, 2006; Wieviorka, 2009). Cabe aclarar que si bien el cuerpo es un elemento central no monopoliza la matriz de diferenciación.

"Villeros", "negros" y "rochos" son adjetivos con cargas de sentido negativas que expresan prejuicios de clase racializados (Margulis, 1999). Allí, subyace un vínculo ideológico entre el nivel socioeconómico (“villeros”) y el modo de comportarse (“chorros”) que se asienta en los rasgos fenotípicos 
(“negros”). Se trata de "un mecanismo de dominación simbólica que establece una doxa penalizante que se traduce en prácticas de intolerancia y estigmatización de los jóvenes y que tiene una de sus expresiones más brutales en el par taxonómico violento-pobre” (Kaplan, 2011: 97).

Los estudiantes son conscientes, hasta cierto punto, del contenido negativo de sus palabras e intentan establecer una escisión entre cuerpo y mente aclarando que cuando utilizan aquellos términos no pretenden discriminar refiriéndose al origen social o al color de piel. Pero la matriz racista opera en un nivel inconsciente.

A: Sin ofender: son negros. No negros de piel, sino negros de mente. Es como...

\section{P: ¿Qué significa ser “negro de mente”?}

A: Que hablás como un negro, así tipo “eh, amigo, eeeh”, todo así, y como que ya tenés inculcado, es como que lo ves por todos lados, quizás o ya es como, ya es tu manera de ser buscar quilombo. Supongo que es eso. Vos ves, ponele, personas así, que son normales, y no están buscando todo el tiempo quilombo. Y dos personas que están escuchando cumbia, que son así todo... Ayy, hablan mal, están todo el tiempo así: ¡buscando quilombo! Es así, es como que se divide en esa línea. (Alumna de 4to. T.T. - Escuela B)

Para estos jóvenes, no es lo mismo ser "negro de piel" que "negro de mente". Se puede ser de un modo sin necesariamente ser del otro. Es decir que se puede ser de tez clara y tener comportamiento de "negro" y ser de tez morena y comportarse de forma "tranquila". La conjunción de las propiedades "negro de piel" y "negro de mente" las y los entrevistados la expresan en la figura estética estereotipada de los "pibes chorros" que designa a los jóvenes que habitan en la villa, delinquen y no tienen buen rendimiento en la escuela. La "cuestión de piel” a la que aluden los estudiantes “(...) remite a la cuestión 
social vinculada al tratamiento de las diferencias y las desigualdades. La piel, en muchas ocasiones, se utiliza como eufemismo del origen de clase: a tales pieles, tales destinos...” (Kaplan, 2016: 212).

A pesar de la diferenciación que elaboran entre las dos "negritudes" podemos evidenciar las huellas de la matriz clásica del racismo (Wieviorka, 2009) sobre la cual se edifica aquel discurso. "Negro de mente" hace alusión a que se comporta como si fuera "negro de piel". La negritud fenotípica pasa a ser negritud del espíritu. Esta asociación metafórica de un atributo físico para describir comportamientos socialmente reprobados forma parte de la operación esencializadora de los discursos racistas.

Lo mismo sucede cuando los estudiantes sostienen que se puede tener "actitudes de villero" sin vivir en una villa como también se puede residir allí y ser "tranquilo". En trabajos precedentes (di Napoli, 2013; Kaplan, 2011a) hemos destacado que la apariencia de "villero", entendido como hábito corpóreo, se la asocia a la de la incivilidad en general, lo que genera una suerte de discurso racista sobre los jóvenes surcados por su condición de marginalidad. Así, las cualidades y/o atributos negativos, y por tanto estigmatizantes, son depositados por antonomasia sobre un sector social subalterno racializado.

Esta asociación dóxica entre el modo de comportarse, los rasgos corporales y el lugar de residencia, a pesar de las justificaciones discursivas que argumentan nuestros entrevistados, forma parte de un sentido práctico de distinción (Bourdieu, 2014b) a partir del cual ellos y ellas orientan sus acciones.

\section{P: ¿Por qué no van a los otros boliches ${ }^{12}$ ?}

L: Y también capaz por lo que te dicen, si es seguro, si van a robar, si van a pelearse. Por la visión que tenés de la clase social esa: de los rochos, los negros, los turros. Tampoco es que discrimino, pero no me

12 "Boliches" refiere a locales bailables. 
va estar con ellos.

P: ¿Cómo los ves?

L: Y peleadores... Sí, son villeros, viste que acá se dice que son villeros

\section{P: ¿Por qué?}

L: Te pelean, te prepotean siempre. Si los mirás "eh que me rebajás, lalala” cosas así.

P: Pero vos me contaste que esto pasa a dónde vos vas, porque hay algunos amigos de tus amigos que hacen eso, ¿ ${ }^{\text {son }}$ iguales los boliches?

L: No hace falta...negro puede ser negro de piel y podes ir a bailar a los boliches que van la mayoría que quiere divertirse, y vas y la pasas bien. Pero si sos negro cabeza que vas a pelear; como estos chicos que pueden ser chicos comunes, bah, comunes en el sentido de que tienen una buena clase social, pueden estar bien vestidos pero tienen esa mente de ir y pelear. Con cosas que también hacen, pero en los boliches esos pasa siempre, pasa seguro.

\section{P: ¿En los otros boliches “pasa seguro”?}

L: Claro, y sí, por esto mismo. Porque ahí sí se juntan todos... la mente es de la villa, mente de villero. De querer ir a pelear, de prepotear, de ser mejor, pensar que mandas. Eso es en la villa y bueno, ahí van las personas villeras... gente villera. No de clase social o no, no tiene nada que ver si sos pobre o rico o más o menos, sino la mente que tenés.

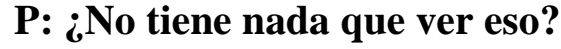

L: No, porque vos podes ver gente que no tiene para tomarse un trago pero va a bailar igual y la pasa bien igual ¿entendés? Y esta gente que 
tiene para pagar un trago, va y pelea igual. Pasan en este boliche por la forma de vestir que tienen, porque visten bien, o porque el padre del pibe puede comprarle la ropa para vestirse. Y los otros chicos como que no, como están siempre de ropa deportiva y tienen otro estilo de vida, también tienen la misma mentalidad de pelearse y todo. Pero capaz que no miden, no tienen esa educación para medir las consecuencias, si te tienen que clavar un cuchillo te lo clavan. No se pelean y termina ahí.

\section{P: Y el otro por ahí sí...}

L: Te pelean y pueden ser unos tarados, villeros también, pero que saben cuándo parar. Se pelean y listo, quedó como el mejor del mundo y si lo cagás a palos se va a ir, no es que va a volver y te va a clavar un cuchillo. No sé si llamarlo villero, pero es como se la llama. (Alumno de 5to. T.M. - Escuela B)

Nuestro entrevistado expresa que prefiere evitar ciertos locales bailables a donde asisten "rochos, negros, turros" porque allí percibe mayor violencia. Primero lo asocia a la clase social y luego, cuando le repreguntamos por las situaciones de violencia que nos había relatado en los boliches a los que él asistía, matiza esa diferenciación. Para varios estudiantes se trata de una cuestión de probabilidades: allí donde asisten jóvenes de sectores sociales con menor capital económico y cultural consideran más probable encontrarse con individuos que tengan comportamientos menos autocoaccionados ("mentalidad de negro"). Luciano también establece una diferencia entre los "negros de mente" con poder adquisitivo y aquellos que tienen pocos recursos económicos. Para él, los primeros tienen una educación que les daría la posibilidad de regular el uso de la fuerza física, en cambio a los segundos los describe como descontrolados. Los matices referidos al autocontrol funcionan como un argumento para establecer distinciones de clase frente a comportamientos similares. 
Estos prejuicios de clase racializados, mediados por el uso de categorías estigmatizantes, los escuchamos en los testimonios de los estudiantes de ambas escuelas. Sin embargo, en la escuela B hallamos mayor uniformidad de estos discursos mientras que en la escuela $\mathrm{A}$ encontramos algunas voces que se adscriben en lo que ciertos estudiantes denominan como “onda negra”. A través de expresiones autoestigmatizantes podemos explorar la eficacia simbólica del poder de la doxa sobre algunos jóvenes que residen en villas, quienes incorporan estos discursos atribuyéndose a sí mismos la negatividad e inferioridad.

A través del par cheto/rocho, una estudiante de la escuela A realiza el mismo cálculo simbólico (Kaplan, 2010), que el estudiante mencionado más arriba de la escuela $B$, para describir el comportamiento de los jóvenes según el nivel socioeconómico.

\section{P: Recién, me dijiste que alguien podría tener aspecto de "rocho" y “ser tranquilo", o podría ser un “cheto" y “ser quilombero". Entonces si vos tenés aspecto de "rocho" (...) ¿Por qué en un caso la excepción es” ser tranquilo" y en el otro es “ser quilombero”?}

K: Y, porque el chetito es como que... se junta con gente más tranquila, y como sabés que se junta con gente más tranquila, pensás que él también es tranquilo, y el rocho si se viste así, es porque seguro que es de una villa, y seguro que para en una esquina, y seguro que se junta con todos los pibes, y seguro que se droga, y seguro que es así.

\section{(Alumna de 3ro. D T.T. - Escuela A)}

En el relato anterior observamos cómo una estudiante, que reside en un asentamiento precario cercano a la escuela A, en base a su experiencia incorpora una serie de preconceptos de orden práctico por los cuales anticipa el comportamiento de las y los jóvenes según su apariencia o autopresentación. 
En otro de los testimonios, un estudiante de la misma escuela menciona que cuando era más pequeño tenía “mentalidad de negro”, la cual considera que la aprendió en su barrio. Se trata de la búsqueda de liderazgo y respeto entre pares a través del uso de la fuerza física.

Nos llevábamos mal, él también era como yo, o sea todo el tiempo queriendo pelear. Capaz que yo venía acá a la [escuela] X y cuando estaba en sexto grado yo y un amigo le pegábamos a todo el mundo... para divertirnos nada más. Pero llegamos acá a séptimo y es otra cosa, te juntas con gente más grande y es otra cosa. Vos estás en tu grado y como venís con esa mentalidad, decís acá voy a mandar yo. Él vino de otra escuela también con esa mentalidad. Entonces chocamos y una vez nos agarramos a piñas acá en el recreo, pero después nos empezamos a llevar bien, y después ya se cortó. (...)

\section{P: ¿Qué significa esto de “mandar”?}

F: Antes mandar era como, para mí, era como estar ahí que todos a mí me iban a respetar, que acá mando que yo te digo esto y hace esto. (Alumno de 4to. T.T. - Escuela A)

Si bien ahora no aprueba esta forma de comportarse reivindica su condición de "negro" y "villero" antes que juntarse con un "blanquito".

Los pibes me dicen negro pero, no me enoja porque a mí me encanta que me digan negro. $\mathrm{O}$ sea, no es por nada pero antes de ser blanquito me gusta ser negro [se refiere con sus ojos al entrevistador, risas]. Pero como te dije antes yo estoy con el tema del rap y me siento más identificado, el rap, gente negra y todas esas cosas... como que es mi mundo, viste. No es que discrimine porque sea blanquito, negro, rojo, verde. Sea como sea yo te voy a respetar pero no hay cosa más fea que me quiera venir a descansar un blanquito, no me lo banco. (...)

Como que me discrimino a mí mismo, como que me aparto de los 
demás como si fuera otra cosa. (...) O sea, hago más amistad con gente de la calle que con gente que se crio en una familia alta digamos, o media alta o como sea. A veces te sentís más identificado con esa gente, y como que o sea, porque lo que son así son agrandados los que se criaron así. (Alumno de 4to. T.T. - Escuela A)

Del testimonio de este estudiante de sectores marginalizados emerge una resignificación del atributo “negro” valorizándolo positivamente. Hace del estigma un emblema en cuanto construye su identidad desde dicha cualidad. Sin embargo, interpretamos que ello le genera cierta tensión cuando termina admitiendo que "se discrimina a sí mismo” al describirse de esa forma.

\section{LA FIGURA ESTÉTICA DE “LOS WACHITURROS”.}

Además de los atributos que hemos mencionado, los estudiantes asocian otras prácticas y hábitos en relación con las y los jóvenes que tipifican como “violentos": la forma de hablar (vocabulario y entonación), la vestimenta y apariencia física (maquillaje, corte de pelo, entre otros) y los gustos musicales (ritmos que escuchan y locales bailables a los que asisten).

A: En realidad no sé por qué son así. Supongo que tiene que ver con las modas también. Porque como antes estaban los floggers con el flequillo y que hablaban cheto; ahora están los rochos. A mí me molesta que sean así, pero tampoco les voy a decir nada porque es su vida, no la mía. Es su forma de ser, yo no soy así. A mí me gusta que me hablen bien, que me digas “hola, cómo estás, todo bien”, así. Que hables normal, que escuches música con auriculares, no en el colectivo como si fuera un boliche. Eso me molesta, porque ponen música toda negra. Entonces vos estás como en un boliche. Lo tenés acá al lado sentado y como que tenés ganas de agarrar el celular y tirárselo por la ventanilla. 


\section{P: Recién me dijiste, "es una moda ser rocho", o algo así. ¿Qué es "ser rocho"?}

A: Es como los cumbieros antes, ¿viste? Bueno, es así, pero ahora tienen ropa más... ponele, pantalones "cagados”, zapatillas Reebook, gorras, cortecito así como para arriba. (...)

\section{P: ¿Qué música escuchan los rochos?}

A: Cumbia. Pero cumbia negra

\section{P: ¿Cuál es la diferencia entre la cumbia y la “cumbia negra”?}

A: Porque está la cumbia tipo cuarteto, tipo algo más romántico, tipo Los del Fuego, que se yo... Rodrigo. Y está Damas Gratis, los Pibes Chorros, esas cosas (...)

\section{P: ¿Cómo les va en la escuela?}

\section{A: Supongo que mal \{Risas\} \\ P: ¿Por qué suponés eso?}

A: No veo a un rocho estudiando, [risas]. Los veo más como saliendo a bailar, a joder, a unas casas, a... no sé. Suponete, hoy estaba subiendo la escalera y en vez de estar los rochos en el curso, veo un rocho besándose una chica en la escalera. (Alumna de 4to. T.T. Escuela B)

A los jóvenes que nominan como violentos los asocian con una determina estética urbana de corte "villero". Hablan en términos de moda en cuanto se trata de una estética asociada originalmente a quienes viven en asentamiento urbanos precarios, pero que también ha sido apropiada por otros grupos de jóvenes que no necesariamente residen allí. Varios entrevistados nos detallan de forma precisa los indicios corporales por los cuales las y los identifican.

Hay algunas personas que por ahí por cómo se visten, por ahí ves a un villero en la calle, villero en la forma de decirte, como se viste por ahí 
con gorras muchos aros o zapatillas todas con resortes, pantalones sueltos; y vos ves y ya te asustás y pensás que te quiere robar o que te quiere lastimar, o que te quiere hacer algo. Igual ahora es como que estás más acostumbrado por que como es la moda, porque todos se visten iguales, antes no se veía tantos chicos vestidos así. (...) Entonces ahora es como que todos se visten igual y no distinguís cuál es el chorro y el que se viste por vestirse. ¿Entendés?

(Alumna de 4to. T.T. - Escuela A)

F: Yo te digo la verdad, generalmente estos pibes, viste cuando vos los ves como se visten, qué sé yo, uno está acostumbrado a decir “estos negros de mierda”, la verdad.

\section{P: Ok, es la palabra que te salga.}

F: Sí, la verdad que... está bien, no, pero lamentablemente es así, porque es la verdad. Vos ves a un pibe que va con gorrita, así, con ropa deportiva y ya pensás mal. Es automático ya...

\section{P: ¿Vos decís que lo tenés internalizado?}

F: Claro, que sé yo, es medio morochito, usa gorrita... y uno se cruza de vereda. Es así, porque los que te roban se visten así, y vos no sabés si ese te va a robar, o no. Por ejemplo, todas las veces que me robaron, los pibes eran así. (Alumno de 4to. T.M. - Escuela B)

De los relatos de las y los estudiantes se observa cómo opera un sentido práctico que asocia dicha estética con jóvenes que rozan la ilegalidad. Justamente, dicen que la expansión de esa moda les dificulta identificar a aquellos que son “chorros” de los que solo tienen la apariencia. Este hexis corporal configura en los estudiantes un sentimiento de amenaza y desconfianza que despierta temor hacia determinados jóvenes. En esa emoción “...se entremezcla la sensación de desprotección y peligro con cierta construcción de sujetos que se activan como agentes de dicha peligrosidad” 
(Kaplan, 2011b, p. 47). Las y los jóvenes de sectores populares, en parte, portan los rostros que operan como causa y como efecto de la incorporación prerreflexiva de esos sentimientos.

A esta estética se le atribuyen cualidades estigmatizantes sustentadas en su negritud. Los figuran como "negros", con "mentalidad de negros", que escuchan "música negra". La diferenciación cromática que se realiza entre los jóvenes expresa la desigual distribución de las luminancias corporales.

El joven adjetivado como "violento" es pintado de negro. Ese color expresa la negación e invisibilización de la subjetividad que la sociedad les atribuye a esos cuerpos. Y cuando son visualizados son identificados como amenaza, foco de peligro. "Se desearía no verlos, pero están ahí, por eso se los evita o se oscurece su presencia a través de la descalificación (di Napoli, 2014: 20).

A lo largo de los testimonios de los estudiantes observamos que la mayoría de los atributos asignados a los jóvenes que tipifican como "violentos" son condensados en la figura estética de "los wachiturros"13.

A: Los wachiturros [risas]. Para mí, son los más violentos. Porque vos viste la junta que tienen, que fuman porro ${ }^{14}$, que se creen capos y tal vez están drogados y te pegan de la nada, así, sin sentido. (...)

\section{P: ¿Acá hay “wachiturros”?}

A: acá hay algunos, pero no mucho.

${ }^{13}$ Los Wachiturros fue un grupo musical de cumbia con fusión de reggaetón de mucha actividad durante los años 2011 y 2012. A los objetivos de este trabajo resulta pertinente destacar el origen semántico del nombre. Proviene de la combinación de 2 palabras: Wachi (deformación del diminutivo de "guacho", que en lunfardo significa "huérfano" y por desplazamiento semántico viene a denotar "pibe", "persona muy joven". También puede significar "mala persona”) y la palabra "turro” (que en lunfardo significa, entre otros sentidos: mal amigo, malintencionado, bribón, maligno, pícaro, perverso, ladino, cobarde o incapaz). [Significados extraídos de: http://www.todotango.com/comunidad/lunfardo/]

${ }^{14}$ Refiere a fumar cigarrillos de marihuana 


\section{P: ¿Cómo los identificás?}

A: Por la ropa, la gorrita o jogging negros. Yo los identifico así, la camperita Adidas azul, las zapatillas de plataforma, de colores. O con aritos, muchos... Igual los aritos no tienen nada de malo, pero... El pelo rapado acá y acá la crestita. (Alumna de 4to. T.M. - Escuela B)

P: ¿Hay chicos en tu escuela que tienen actitudes que para vos son violentas?

B: Si, mis compañeros.

\section{P: ¿Qué nos podés contar?}

B: Están todos juntos siempre, además son todos Wachiturros.

(Bárbara, 4to. T.T. - Escuela A)

P: ¿Por qué en un boliche como $\mathbf{N}$. esconden piedras y siempre hay “piñas”?

M: Es un estilo más... ¿Viste Wachiturros? Más tipo Wachiturros, y esos como que son los más jodidos. Son los más quilomberos, buscan así peleas por cualquier cosa. (...)

\section{P: ¿Los que van a los otros boliches cómo son?}

M: Los otros boliches son más tranquis porque nosotros... ojo que hay quilombos pero no son tantos como con cuchillos, piñas y todo eso. Hay discusiones, como que se quieren pelear pero los separan, no se llegan a pelea. Pero a esos boliches como “N.” pueden ir con zapatillas de resorte, vinchas, así bien Wachiturros. En cambio a donde vamos nosotros tenés que ir con zapatos, ropa así de vestir. (...) Está bueno porque no hay muchos Wachiturros. Pasan a veces cumbia pero ellos no están. Esta bueno ese boliche porque no hay tanta violencia como en los otros. Me gusta más. (Alumna de 4to. T.T. - Escuela A) 
Los Wachiturros fue un grupo musical argentino de cumbia cuyas canciones y estilo tuvo una amplia difusión fundamentalmente en los sectores de menores recursos económicos (de donde también provenían sus miembros). Su imagen se erige como una estética urbana asociada a lo subalterno.

Recuperando el modelo teórico de la figuración entre Establecidos y Outsiders que propone Elias (1998), podríamos decir analíticamente que la mayoría de las y los entrevistados construyen una imagen de un nosotros posicionados como establecidos adjudicándose un valor social superior mientras que a través de la caracterización de la figura de "los wachiturros" ponen en juego una serie de categorías estigmatizantes, ya disponibles en el entramado social, con las cuales catalogan a ciertos jóvenes como de menor valor social posicionándolos como outsiders.

Aquellos estudiantes entrevistados que portan este estilo nos manifiestan que perciben las miradas estigmatizantes que se posan sobre ellos. Un alumno de la escuela A nos contaba que su forma de vestirse era motivo de burla por parte de sus compañeros; "parecés wachiturro" le decían. En la misma línea, otra alumna de la escuela B nos decía lo siguiente:

\section{P: ¿Vos que estilo tenés?}

E: Yo digamos que soy más común, la verdad soy más común tirando a rocha...

\section{P: ¿Por qué? ¿Cómo sería esa comparación?}

E: Siento que sí porque la gente que me mira en la calle piensa que soy rocha de mente, pero la verdad no tengo esa mentalidad, o sea a mí me gusta todo. Si vos me ves pensás que yo escucho cumbia, y obviamente que escucho cumbia, a mí me gusta, de hecho bastante, a mi papa le gusta el rock y toda la música, así que se bastante de eso también. Qué se yo, por las zapatillas Reebook que todos los rochos usan. 


\section{$P: \dot{A}$ vos te gusta ese tipo de ropa?}

E: Si me gusta, me parece normal...

\section{P: En un momento me decís que: "piensan que soy rocha de mente" ¿cómo es?}

E: Claro porque, vos ves una rocha por la calle y vos pensás que es una negra que viste, como dicen que va a tener hijos, para cobrar el salario familiar, estereotipos... Y bueno seguramente van a pesar que yo voy a hacer eso,

\section{P: O sea que vos tenés apariencia de...}

E: Si, tengo esa apariencia... Yo no me considero digamos una negra de mente.

\section{(Alumna de 5to. T.T. - Escuela B)}

Quien porta los rasgos y atuendos típicos de la estética "wachiturra" o "rocha", debe cargar con los estereotipos que se depositan sobre sí. Estereotipos que los mismos estudiantes que los sufren los reproducen cuando establecen diferencias entre tener apariencia de "negra" y ser "negra de mente".

Por otra parte, observamos que la figura de "los wachiturros" es utilizada por las y los estudiantes como un indicador para "medir" el nivel de peligrosidad o de violencia de un lugar (ya sea una escuela o un boliche) a través de la cantidad de jóvenes que hubiera portando el hexis corporal con el que se los y las caracteriza. No es casual que los entrevistados, al caracterizar a sus pares, recurran a las actividades nocturnas para hacer explicitas las diferencias. El boliche a donde suelen ir a bailar es el espacio social al que más aluden para establecer las distinciones entre el par cheto/negro.

Las y los entrevistados de la escuela A hacen mayor referencia a la presencia de compañeros tipificados como "wachiturros" que los de la escuela $\mathrm{B}$, incluso los identificaban como un colectivo particular. A su vez, en ambos 
colegios varios estudiantes del turno mañana argumentan que a la tarde asisten más jóvenes que portan ese estilo. En correspondencia con esa figura, la mayoría de estudiantes de la mañana describe a sus compañeros del otro turno como menos autorregulados y con menor rendimiento escolar en comparación con ellos.

\section{P: ¿Qué imagen tenés de los chicos que vienen acá a la tarde?}

A: No quiero así, a ver, ser racista ni nada pero, pero como que los veo todos así como medio wachiturros, todos así [risas] (...). Venís al colegio y quizás están todas las mesas... no te digo, hay chicos de la mañana que escriben los bancos, pero cuando llegas están todos escritos y te da un aspecto sucio. (Alumna de 4to. T.M. - Escuela B)

\section{P: ¿Cómo son los chicos de la tarde?}

L: Igual digamos, son todos wachiturros [risas]. O sea, viste que los de la mañana son todos tranquilos, vos ves acá y son todos tranquilos. Los de la tarde, vos salís al mediodía, vos ves uno con 500 piercings en la cara, con la colita acá, con ropa todo flúor, de colores, andan así, parecen un arco iris [risas]

\section{P: ¿Acá no hay chicos así?}

L: Si, hay grupos... por ejemplo L. es así. La escuchas y decís...

\section{P: ¿Y los de la tarde son así?}

L: Si. Y todos los amigos de ella están a la tarde. (Alumna de 4to. T.M. - Escuela A)

Respecto de la imagen que tienen los estudiantes de la tarde de sus pares de la mañana, observamos que algunos pocos no notan diferencias entre sí, mientras que la gran mayoría coincide con la imagen que les asignan los alumnos de la mañana, sosteniendo que en ese turno son "más tranquilos", "hay mejor ambiente" o "son más exigentes". Asimismo, algunos estudiantes de la 
escuela B se quejan de que los compañeros del turno mañana se adjudican un valor social superior, en palabras de una de las estudiantes: "son muy creídos $^{15}$ ".

\section{P: ¿Cómo se llevan ustedes con los estudiantes de la mañana?}

M: Bien... yo tengo la mayoría de mis compañeros que se pasaron a la mañana, por cuestión que la mañana es mejor que la tarde...

P: ¿Por qué?

L: Hay mejor ambiente

M: Si, dicen que es más exigente

\section{P: ¿Los profesores son más exigentes?}

M: Si, yo me doy cuento porque, a la mañana están más adelantados que nosotros. Es más tranquilo, porque la mayoría van todos dormidos porque levantarse a las 6 de la mañana.

\section{P: ¿Por eso son más tranquilos?}

M: Digamos que están con ganas de dormir, o sea, no tienen ganas de hacer nada...

L: Es más a la mañana nunca hubo problema...

M: A la mañana no, siempre a la tarde hay.

L: Cuando nosotras llegamos vemos que todos salen se saludan, todos re bien

\section{(Alumnas de 4to. T.T. - Escuela B)}

Aquí podemos ver como al interior de las escuelas también se erige una figuración entre establecidos y outsiders (Elias, 1998) donde los estudiantes de la mañana se creen esencialmente superiores asignándoles a sus pares de la

\footnotetext{
${ }^{15}$ La frase hace referencia a "ser soberbios".
} 
tarde categorías despreciativas. Al mismo tiempo, gran parte de las y los entrevistados del turno tarde asumen esa imagen aunque no les gustase. Los efectos de estás operaciones de clasificación social son el resultado de una lucha simbólica atravesada por las relaciones de poder desiguales entre los actores que las utilizan (Bourdieu, 2012, 2014b). El proceso de inferiorización se vincula a las imágenes y auto-imágenes que construyen relacionalmente las y los jóvenes en el escenario escolar en tanto microcosmos social.

\section{Conclusiones}

Hemos analizado una serie de dimensiones sobre las percepciones que construyen las y los estudiantes de educación secundaria en torno a la figura del "violento". Partimos del supuesto de que dicha tipificación no es un acto de nominación neutro, sino que se enmarca en un complejo sistema de clasificación socialmente jerarquizado. La categorización dicotómica de "violento/no violento" implica un juicio de valor por el cual se busca delimitar las fronteras entre un nosotros y ellos.

El par autocontrol/descontrol es uno de los primeros ejes sobre los cuales se tipifican como "violentos". A ellos los describen como individuos poco autoaccionados en su forma de comportarse. Serían quienes buscan permanentemente la confrontación, en muchas ocasiones recurriendo al uso de la fuerza física.

Asimismo, en la construcción simbólica de la imagen del "violento" que realizan los estudiantes, observamos cómo se conjugan una serie de atributos estigmatizantes que van más allá de la forma de comportarse y apuntan a la disposición corporal y al origen social de los jóvenes. A lo largo de sus relatos, las y los entrevistados utilizan términos peyorativos tales como "negros", “villeros" y "rochos". Estas adjetivaciones evidencian expresiones de racismo y operan como actos de distinción jerarquizante que los ubica en posiciones 
inferiores del espacio social y simbólico. Esta forma de taxonomía escolar puede asociarse al discurso hegemónico que asocia el nivel socioeconómico con determinadas acciones delictivas a partir de rasgos corporales. El cuerpo representa el principal elemento donde se posan las miradas condenatorias. En nuestro caso, encontramos sintetizados los atributos mencionados por los estudiantes en la figura estética de “los wachiturros”.

En sus relatos algunos jóvenes matizan los discursos estigmatizantes a partir de la diferenciación de dos “negritudes” que no necesariamente estarían conectadas de forma causal: aquella que hace alusión a un rasgo fenotípico ( "negro de piel”) de aquella que refiere a una forma de comportarse violenta ( “negro de mente”). Sin embargo, en esta asociación metafórica de un atributo físico para describir comportamientos socialmente reprobados hallamos las huellas discursivas del racismo clásico.

Por otra parte, cuando existen similitudes entre las formas de comportarse, los gustos estéticos o las marcas corporales entre quienes son caracterizados como "violentos" y quienes producen dicha nominación, emergen diferenciaciones de forma referidas, nuevamente, al control de las emociones. Si en los locales bailables a los que asisten también hay peleas, argumentan que son más esporádicas o sin armas en comparación a donde asisten "los wachiturros". Si tienen amigos que se pelean en los boliches los diferencian de quienes califican como “villeros” en cuanto “saben cuándo parar". Si escuchan la misma música, cumbia, se diferencian en que "los rochos” la escuchan a un alto volumen en espacios públicos que los incomoda. Y si visten la misma ropa, dicen no tener la misma “mentalidad de negro". Siguiendo la línea de pensamiento de Bourdieu y Elias, podemos interpretar que la autorregulación de las emociones y los cuerpos en la convivencia social se erige en un signo de distinción social.

Para finalizar, cabe destacar que los procesos de etiquetamiento tienen un efecto simbólico en la constitución de subjetividad. En la institución educativa 
las y los estudiantes tejen una trama vincular que configura su experiencia escolar dejando marcas subjetivas. Las dinámicas de poder estigmatización entre los grupos escolares, cuyos mecanismos pretendemos descifrar y comprender en nuestros procesos de investigación, pueden contribuir a través de los modos naturalizados de nominación a procesos de inferiorización social que se expresan en adjetivaciones de auto-humillación escolar.

\section{REFERENCIAS BIBLIOGRÁFICAS}

Abramovay, M. (2006): Cotidiano das escolas: entre violências. Brasilia: UNESCO-SECAD.

Aymard, M. (1991): Amistad y convivencia social. En P. Ariès, G. Duby, \& R. Chartier, Historia de la vida privada. La comunidad, el Estado y la familia en los siglos XVI-XVIII, Tomo 6. Madrid: Taurus.

Bourdieu, P. (1990). La «juventud» no es más que una palabra. Sociología y Cultura. México: Grijalbo.

Bourdieu, P. (1999): Meditaciones pascalianas. Barcelona: Anagrama.

Bourdieu, P. (2012): La distinción: criterio y bases sociales del gusto. Buenos Aires: Taurus.

Bourdieu, P. (2013). La miseria del mundo. Buenos Aires: Fondo de Cultura Económica.

Bourdieu, P. (2014a): Describir y prescribir: las condiciones de posibilidad y los límites de la eficacia política. En ¿Qué significa hablar? Economía de los intercambios lingüísticos. Buenos Aires: Akal.

Bourdieu, P. (2014b): ¿Qué significa hablar? Economía de los intercambios lingüísticos. Buenos Aires: Akal.

Bourdieu, P. \& Eagleton, T. (2003): Doxa y vida cotidiana: una entrevista. En S. Žižek. Ideología: un mapa de la cuestión. Buenos Aires: Fondo de Cultura Económica.

Castorina, J. A. \& Kaplan, C. V. (2006). Violencias en la escuela: una reconstrucción crítica del concepto. Violencias en plural. Sociología de las violencias en la escuela. Buenos Aires: Miño y Dávila.

De Swaan, A. (2011). Regresión al Servicio del Estado: Reflexiones sobre la Violencia Masiva». Subje/Civitas, Nº 8. 
Di Napoli, P. (2013). Violencia, racismo y escuela. El caso de los alumnos tipificados como violentos. Propuesta Educativa, $\mathrm{N}^{\circ} 39$.

Di Napoli, P. (2014). Miedo, inseguridad y violencia. Sensibilidades sobre los jóvenes en América Latina. Revista Estudiantil Latinoamericana de Ciencias Sociales, $\mathrm{N}^{\circ} 4$.

Di Napoli, P. (2017). Sociabilidades juveniles en el ámbito escolar. Un análisis de los motivos de acercamiento y distanciamiento entre estudiantes secundarios de Argentina. Revista Mexicana de Investigación Educativa, $X X I I, \mathrm{~N}^{\circ} 73$.

Durkheim, E., \& Mauss, M. (1996). Sobre algunas formas primitivas de clasificación. Contribución al estudio de las representaciones colectivas. E. Durkheim, Clasificaciones primitivas (y otros ensayos de antropología positiva). Barcelona: Ariel.

Elias, N. (1998). Ensayo teórico sobre las relaciones entre establecidos y marginados. La civilización de los padres y otros ensayos. Bogotá: Norma.

Elias, N. (2011). El proceso de la civilización. Investigaciones sociogenéticas y psicogenéticas. México: Fondo de Cultura Económica.

Furlan, A. (Ed.). (2012). Reflexiones sobre la violencia en las escuelas. México: Siglo Veintiuno Editores.

Garriga Zucal, J. (2010). «Nosotros nos peleamos»: violencia e identidad de una hinchada de fútbol. Buenos Aires: Prometeo Libros.

Goffman, E. (2006). Estigma. La identidad deteriorada. Buenos Aires: Amorrortu.

Kaplan, C.V. (1992). Buenos y malos alumnos. Descripciones que predicen. Buenos Aires: Aique.

Kaplan, C.V. (2008). Talentos, dones e inteligencias: el fracaso escolar no es un destino. Buenos Aires: Colihue.

Kaplan, C.V. (2009). Violencia escolar bajo sospecha. Buenos Aires: Miño y Dávila.

Kaplan, C.V. (2010). Filosofía del don y taxonomías escolares. Las construcciones simbólicas de los profesores como mediaciones. Educación, Lenguaje y Sociedad, N 7.

Kaplan, C.V. (2011a). Jóvenes en turbulencia. Miradas críticas contra la criminalización de los estudiantes. Propuesta Educativa, № 35.

Kaplan, C.V. (2011b). La sensibilidad por la violencia como experiencia cultural y educativa en sociedades de desigualdad. El caso de los jóvenes. Cadernos de Estudos Sociais, Vol. 25, N 1. 
Kaplan, C.V. (2012). Mirada social, exclusión simbólica y autoestigmatización. Experiencias subjetivas de jóvenes de educación secundaria». En C. V. Kaplan, L. F. Krotsch, \& V. Orce, Con ojos de joven Relaciones entre desigualdad, violencia y condición juvenil. Buenos Aires: Editorial de la Facultad de Filosofía y Letras (UBA).

Kaplan, C.V. (2013a). El miedo a morir joven. Meditaciones de los estudiantes sobre la condición humana. Culturas estudiantiles: sociología de los vínculos en la escuela. Buenos Aires: Miño y Dávila.

Kaplan, C.V. (2013b). La persistencia de la desigualdad. En C. V. Kaplan \& C. Bracchi (Ed.), Imágenes y discursos sobre los jóvenes. La Plata: Universidad Nacional de La Plata. Facultad de Humanidades y Ciencias de la Educación.

Kaplan, C.V. (2016). El lenguaje es una piel. Género, violencia y procesos civilizatorios. Género es más que una palabra. Buenos Aires: Miño y Dávila.

Kornblit, A. L. (Ed.) (2008). Violencia escolar y climas sociales. Buenos Aires: Biblos.

Le Breton, L. (2010). Rostros. Buenos Aires: Letra Viva.

Margulis, M. (1999). La racialización de las relaciones de clase». En M. MARGULIS \& al., La segregación negada. Cultura y discriminación social. Buenos Aires: Biblos.

Mejía Hernández, J. M. (2013). Relaciones sociales y violencias entre adolescentes de secundaria. Tesis doctoral. Centro de Investigación y de Estudios Avanzados del Instituto Politécnico Nacional, México. Recuperado a partir de http://www.die.cinvestav.mx/LinkClick.aspx?fileticket=bYIDezkceQ8\%3 D\&tabid=23

Míguez, D. (2008). Violencias y conflictos en las escuelas: aproximaciones a una problemática actual. Buenos Aires: Paidós.

Miles, M. B. \& Huberman, A. M. (1994). Qualitative data analysis: an expanded sourcebook. Thousand Oaks: Sage Publications.

Muchembled, R. (2010). Una historia de la violencia del final de la Edad Media a la actualidad. Madrid: Paidós.

Noel, G., \& Garriga Zucal, J. (2010). Notas para una definición antropológica de la violencia: un debate en curso. Antropología y Ciencias Sociales, $\mathrm{N}^{\circ}$ 9. Recuperado a partir de http://ppct.caicyt.gov.ar/index.php/publicar/article/view/1191 
Paulin, H. L., \& Tomasini, M. (2008). Conflictos en la escuela secundaria: diversidad de voces y miradas. Córdoba: Universidad Nacional de Córdoba.

Sáez, V. (2015). Una mirada a la investigación sobre medios, violencia y escuela. Entramado, Vol. 11, № 1.

Viscardi, N. (2002). Violencia en el espacio escolar en Uruguay: prácticas, respuestas y representaciones. Delito y Sociedad, Vol. 1, N 17.

Wieviorka, M. (2009). El racismo: una introducción. Buenos Aires: Gedisa.

Recepción de artículo: noviembre 2016

Aceptación de artículo: mayo 2017 